\title{
Alcohol behaviors across perceived parental security profiles in adolescents
}

McKay, Michael; Perry, John ; Harvey, Séamus; Andretta, James

\section{Journal of Child \& Adolescent Behavior}

DOI:

$10.4172 / 2375-4494.1000322$

Published: 25/11/2016

Publisher's PDF, also known as Version of record

Cyswllt i'r cyhoeddiad / Link to publication

Dyfyniad o'r fersiwn a gyhoeddwyd / Citation for published version (APA):

McKay, M., Perry, J., Harvey, S., \& Andretta, J. (2016). Alcohol behaviors across perceived parental security profiles in adolescents. Journal of Child \& Adolescent Behavior, 4(6), [322]. https://doi.org/10.4172/2375-4494.1000322

\footnotetext{
Hawliau Cyffredinol / General rights

Copyright and moral rights for the publications made accessible in the public portal are retained by the authors and/or other copyright owners and it is a condition of accessing publications that users recognise and abide by the legal requirements associated with these rights.

- Users may download and print one copy of any publication from the public portal for the purpose of private study or research.

- You may not further distribute the material or use it for any profit-making activity or commercial gain

- You may freely distribute the URL identifying the publication in the public portal ?
}

Take down policy

If you believe that this document breaches copyright please contact us providing details, and we will remove access to the work immediately and investigate your claim. 


\title{
Alcohol Behaviors across Perceived Parental Security Profiles in Adolescents
}

\author{
Michael T McKay ${ }^{1 *}$, John L Perry², Séamus A Harvey ${ }^{3}$ and James R Andretta ${ }^{4}$ \\ ${ }^{1}$ Department of Psychological Sciences, University of Liverpool, UK \\ ${ }^{2}$ Department of Sport, Health and Exercise Science, University of Hull, UK \\ ${ }^{3}$ Bangor University, UK \\ ${ }^{4}$ Superior Court of the District of Columbia, Washington, D.C., USA
}

\begin{abstract}
Background: Previous research has suggested a bivariate or correlational relationship between attachment scores and alcohol use behaviors among adolescents.

Methods: The present study is a person-oriented analysis of the association between perceived parental security and alcohol behaviors in Northern Irish adolescents $(N=1,126,61 \%$ male, school grades 8 to 12 ; aged 12 to 16 years).

Results: Model-based clustering of Inventory of Parent and Peer Attachment-Revised (IPPA-R) scores yielded five profiles: (a) High Security ( $n=146,13 \%)$, (b) Moderately High Security $(n=371,33 \%)$, (c) Ambivalent Security ( $n=344,31 \%)$, (d) Moderately Low Security $(n=198,18 \%)$, and (e) Low Security ( $n=67,6 \%)$. High Security adolescents perceived high levels of communication and trust with, and low levels of alienation from, parents. Alcohol use ranked from least to highest in the order provided above.

Conclusions: When compared to peers with High Security profiles, adolescents with Low Security profiles were almost 8 times more likely to be moderate drinkers and 55 times more likely to be problematic drinkers than abstainers.
\end{abstract}

Keywords: Parent attachment; Perceived parental security; Drinking behaviors; Addictive behaviors; Person-oriented analysis; Model-based clustering

\section{Introduction}

\section{Alcohol behaviors across perceived parental security profiles in adolescents}

The Inventory of Parent and Peer Attachment [1] is an index of three perceived parental security dimensions in late adolescents and young adults. The IPPA is intended to assess the extent to which youth perceive both trust and open lines of communication in their relationships with parents. IPPA items are also used to examine feelings of alienation from parents. Gullone and Robinson [2] revised the wording of IPPA items with the aim to simplify the language for use in children and younger adolescents, while retaining a theoretically consistent scale (i.e., IPPA-Revised). Many scholars have used the IPPA and the IPPA-R to examine the association between perceived parental security and alcohol behaviors [3].

One limitation in this literature has been an almost exclusive focus on correlations between IPPA/IPPA-R scores and scores on assessments of alcohol use. Correlations are quantifications of the average association between scores on two variables in a population or sample. However, it is not likely that individuals hold each dimension of perceived parental security to the same degree, which is an assumption that must be made while interpreting a correlation table that includes both multiple perceived parental security factors and outcomes. Instead, it is more likely that individuals hold each dimension of perceived parental security to varying degrees.

In person-oriented analysis, individuals are grouped together based on similarities in scores across a set of target variables prior to the examination of outcomes [4]. Theoretically, the process of grouping is intended to reveal latent classes. Therefore, the variables being used to group individuals must each contribute to, or account for, a psychological construct. For example, cluster analysis has been applied to scores on six subscales that account for positive and negative attitudes toward the past, present, and future, which has yielded time attitude profiles in adolescents [5]. Cluster analysis has also been applied to scores on six subscales intended to assess racial identity attitudes, which has yielded racial identity profiles in adolescents [6]. Both time attitude profiles and racial identity profiles have been shown to have meaningful relationships with other variables of consequence in adolescents.

Andretta et al. [7] recently used model-based clustering of IPPA scores to examine perceived parental security profiles in African Americans involved in the juvenile justice system. Model-based clustering is a method of applying finite mixture modeling to the identification of clusters that are homogenous within groups and heterogeneous between groups with regard to a set of variables [8]. In total, Andretta et al. [7] identified four profiles: (a) Low Security ( $n=36,17 \%)$, (b) Moderately Low Security $(n=62,29 \%)$, (c) Moderately High Security $(n=71,33 \%)$, and (d) High Security $(n=44,21 \%)$. When compared to peers, adolescents with High Security profiles were identified by high levels of communication and trust $(\approx+1 S D)$ alongside low levels of alienation $(\approx-1 S D)$. Low Security adolescents reported IPPA score profiles that were opposite to those reported by

${ }^{*}$ Corresponding author: Michael T McKay, Department of Psychological Sciences, University of Liverpool, UK, Tel: 07875778186; E-mail: Michael.McKay@liverpool.ac.uk

Received October 31, 2016; Accepted November 17, 2016; Published November 25, 2016

Citation: McKay MT, Perry JL, Harvey SA, Andretta JR (2016) Alcohol Behaviors across Perceived Parental Security Profiles in Adolescents. J Child Adolesc Behav 4: 322. doi:10.4172/2375-4494.1000322

Copyright: (c) 2016 McKay MT, et al. This is an open-access article distributed under the terms of the Creative Commons Attribution License, which permits unrestricted use, distribution, and reproduction in any medium, provided the original author and source are credited. 
High Security peers, with the two moderate groups falling between the poles. The largest differences in outcomes were observed between High Security and Low Security adolescents. Specifically, adolescents with High Security profiles reported substantially higher levels of prosocial behavior (Cohen's $d=1.37$ ), and meaningfully lower levels of depression (Cohen's $d=-1.02$ ), anxiety (Cohen's $d=-0.97$ ), and oppositional defiance (Cohen's $d=-1.41$ ) when compared to peers with Low Security profiles.

\section{Perceived parental security and alcohol behaviors}

Many studies have focused on the effect parents have on adolescent drinking behaviors. Yet, few studies have focused on how parent attachment contributes to drinking behaviors specifically, and where the topic has been researched results have been mixed. Some cross-sectional research has demonstrated a link between a higher risk of substance use (including alcohol use) and less secure parental attachment $[9,10]$. Meanwhile other research has shown no association between alcohol use behaviors and parental attachment [11] including in longitudinal studies on the subject. For example, van der Vorst, Engels, Meeus, and Dekovic [12] studied IPPA scores in a large sample of adolescents $(N=1,012)$ and found that across a year, parent attachment did not have an effect on drinking behaviors. On the other hand, poor parent attachment was associated with the onset of drinking at a young age.

The complexity of the inter-play between attachment and parenting variables was further demonstrated in a recent UK study that included the IPPA-R. McKay [3] reported that when comparing abstainers and moderate drinkers, and accounting for school grade and gender, less strict parental rules, but not parental or peer attachment was significantly associated with drinking behavior. However, when comparing moderate and more problematic drinkers, more problematic drinking was associated with reduced parental attachment, higher peer attachment and less strict parental rules on drinking. In a similar study, Nash et al. [13] reported that greater parental disapproval of drinking was negatively associated with drinking in adolescents. Henry, Oetting, and Slater [14] assessed family attachment in adolescents with three items: "My family cares about me," "I care about my family," and "My family cares about what I do." Using a latent growth model to assess development across a two-year period, these authors showed that adolescents who reported a strong attachment with family also reported less drinking behaviors than peers who reported weaker family attachments.

\section{The present study}

Previous research has shown that attachment security is a protective factor, and that attachment insecurity is a risk factor, for drinking behaviors. Therefore, if identified, we hypothesized that the highest percentage of abstainers from alcohol consumption would be observed in adolescents with a High Security profile, and the highest percentage of problematic drinkers would be observed in adolescents with a Low Security profile. Moderately High and Moderately Low Security adolescents were hypothesized to fall between the two poles regarding alcohol behaviors. Given the results of the Nash et al. (2005) and McKay (2015) studies, we further posited that higher levels of parent rules about drinking would be associated with lower levels of drinking in adolescents. Due to the exploratory nature of the third research question, no specific hypotheses were generated regarding the association between parent rules about drinking and perceived parental security profiles. The present study was to employ modelbased clustering to IPPA-R scores, and to identify perceived parental security profiles in a large sample of Northern Irish (NI) adolescents $(N=1126)$. Based on the IPPA groups reported by Andretta et al. (2015), we hypothesized to observe at least four profiles: (a) High Security, (b) Low Security, (c) Moderately High Security, and (d) Moderately Low Security.

\section{Method}

\section{Participants and procedure}

Data included 1,126 Northern Irish, high school students $(61 \%$ male, grades 8 to 12, aged 12-16 years). Participants were from 12 high schools in the greater Belfast area. Each participating school was asked to provide around 20-25 pupils from each of grades 8 (age 12) through 12 (age 16). Schools were purposively chosen to reflect the overall demographics of the area (Catholic versus State schools; academicallyfocused Grammar schools versus more vocational Secondary schools). All schools approached agreed to participate.

Parents of participants were provided with information about the study, and given an opportunity to exclude their child from participation. No parents withheld consent for their children to participate. The University Ethics Committee at the second author's institution approved the consent form, which was completed by youth on the day of data collection following an explanation of the study. The setting for data collection was similar to test-taking conditions, and collection took approximately 40 minutes. Researchers and field workers assisted participants where necessary with any issues of comprehensibility in order to ensure no missing data.

As the data were clustered at the school level (i.e. pupils within schools), a set of dummy variables was fitted to take account of the non-independence of study respondents at the school level. Given the relatively small number of schools (clusters), multi-level modeling analyses were not viable. For such analyses, it has been suggested that a sample of 50 clusters (schools) or less leads to biased estimates of the second-level standard errors [15]. A total of 23 questionnaires were discarded because of their having been spoiled (multiple answers for all items). However, there were no additional problems with data collection (e.g., missing data).

\section{Measures}

The parent focused items of a revised version [2] of the Inventory of Parent and Peer Attachment was used (IPPA; [1]). The IPPA-R includes 28 items used to assess perceived parental security. Youth endorse the degree to which they agree with each item on a 5-point Likert scale ranging from almost never true or never true to almost always true or always true. The IPPA-R includes three factors: (a) communication ( $\alpha$ parent $=.83$ ), (b) trust ( $\alpha$ parent $=.88$ ), and $(\mathrm{c})$ alienation ( $\alpha$ parent $=.80$ ). The structural validity, internal consistency, and validity of IPPA-R scores have been substantiated in studies that have included adolescents $[2,12]$.

Drinking behaviors were assessed using the Adolescent Alcohol Involvement Scale (AAIS; [16]). The AAIS includes 14-items, and scores between 0 and 79 are used to classify respondents into 5 categories namely: abstainers $=0$; 'normal' (those who rarely drink) adolescents $=1-19$; adolescents who drink but do not experience problems $=20-41$; alcohol misusers $=42-57$ and 'alcoholic-like' drinkers $=58-79$. Mayer and Filstead [16] reported internally consistent AAIS scores, and adequate test-retest reliability of AAIS scores. Further, Mayer and Filstead [16] reported that the average internal consistency of AAIS was shown to be .86 in meta-analyses of studies to include the index ( $\alpha$ present study $=0.78$ ). In a recent study in NI, McKay and Dempster, [3] provided evidence for the psychometric validity and 
internal consistency $(\alpha=0.84)$ of the AAIS in a large adolescent sample $(n=4600)$.

Parent rules about drinking were assessed using the - The Rules about Alcohol Questionnaire (RAQ; [17,18]). The RAQ includes 10 items, and for each item respondents endorse the degree to which their parents set rules around drinking (1=completely acceptable to $5=$ completely unacceptable; $\alpha$ present study $=0.88)$. Internal consistency of RAQ scores has been shown in adolescents (e.g., .83 $\geq a \leq 0.89$; [18]).

\section{Results}

IPPA-R scores were not skewed or kurtotic with the exception that trust scores were consolidated around the mean (i.e., kurtosis=4.84). Other descriptive statistics and intercorrelations of IPPA-R scores are shown in Table 1. Correlations among IPPA-R scores were moderate, and in keeping with theory. That is, a positive association between communication and trust was observed, and negative correlations were observed between alienation and the other IPPA- $\mathrm{R}$ subscale scores. Correlations between parent rules about drinking and IPPA-R scores were small, the largest being positive and between parent rules and communication.

\section{Model-based clustering of IPPA-R scores}

The mclust package in $R$ statistics was used to develop modelbased clustering of IPPA-R scores $(\mathrm{N}=1,126 ;[19,20])$. Model-based clustering uses finite mixture modeling to determine a set of probability distributions, each probability distribution being a latent class or cluster [21]. Mclust applies 10 parameterizations across one to nine possible cluster solutions.

Results yielded three optimal solutions as assessed by three fitstatistics (Table 2), which pointed to a four or five cluster solution. Average posterior probabilities $(A P P)$ were calculated for the cluster solutions, and higher probabilities were observed across the five-cluster solution (Figure 1) than the more optimal of the two four-cluster solutions $(0.86,0.79,0.82,0.76)$. Third, $T$-scores for each IPPA-R subscale were plotted, and results showed five distinct profiles (Figure 1). To further validate the five-cluster solution as recommended by

\begin{tabular}{|l|c|c|c|c|c|c|}
\hline \multicolumn{1}{|c|}{ Measure } & M & SD & $\mathbf{1}$ & $\mathbf{2}$ & $\mathbf{3}$ & $\mathbf{4}$ \\
\hline 1. Communication & 36.73 & 7.45 & -- & & & \\
\hline 2. Trust & 42.41 & 6.68 & 0.78 & -- & & \\
\hline 3. Alienation & 18.37 & 6.08 & -0.67 & -0.72 & -- & \\
\hline 4. Parent Alcohol Rules & 41.73 & 8.32 & 0.2 & 0.18 & -0.11 & -- \\
\hline
\end{tabular}

Note: M: mean; SD: standard deviation; $p$-value $\leq 0.001$ where $r \geq 0.11$. Power analyses using the pwr package in $R$ statistics showed that an $r$ coefficient of 0.10 was the cutoff for a minimally interpretable correlation (italics). Power was set to the recommended level of 0.80 [41], and significance level was determined using Bonferroni's adjustment (i.e., $\mathrm{p}=0.01$ )

Table 1: Descriptive statistics for inventory of parent and peer attachment-revised scores and parent alcohol rules.

\begin{tabular}{|c|c|c|c|c|c|}
\hline $\begin{array}{c}\text { Number of } \\
\text { Components }\end{array}$ & df & Parameterization & BIC & ICL & I \\
\hline 4 & 39 & VVV & -20052.7 & -20540.5 & -9889.35 \\
\hline 4 & 33 & VEV & -20052.4 & -20620.7 & -9910.27 \\
\hline 5 & 33 & VVV & -20049.3 & -20459.3 & -9905.22 \\
\hline
\end{tabular}

Note: The mclust package in R-statistics returns the three most optimal models for the data. VEV: ellipsoidal, equal shape; VVV: diagonal, varying in volume and shape. BIC: Bayesian Information Criterion, ICL: Integrated Completed Likelihood, I: Log-likelihood. The optimal solution is highlighted in italics.

Table 2: Gaussian Finite Mixture Models Fitted by Expectation-Maximization Using IPPA-R Parent Scores (Northern Ireland Data; N=1126).
Mun, von Eye, Bates, and Vaschillo [22], model-based clustering was run a second time using a randomly selected $75 \%$ of the sample. Using the mcclust package in $R$ statistics, an Adjusted Rand Index (ARI) showed substantial overlap in cluster assignments when including the entire and randomly selected samples (ARI=0.90; [23]).

The first profile was characterized by extremely low levels of communication and trust with parents $(\geq-2 S D)$ alongside elevated feelings of alienation $(\approx+2 S D)$, and was therefore labeled Low Security (See Figure 1). The second profile included adolescents with communication and trust scores slightly above the mean $(\approx+0.5 S D)$, and scores for alienation $(\approx-0.5 S D)$ that fell just below the mean: Moderately High Security. The third profile was labeled High Security due to comparatively elevated levels of communication and trust with parents $(\approx+1 S D)$ coupled with low scores for alienation $(\approx-1 S D)$. Adolescents with an Ambivalent Security profile reported average scores across all three IPPA-R subscales. The fifth profile was characteristic of adolescents with moderately depressed scores for communication and trust $(\approx-1 S D)$, and moderately elevated alienation scores $(\approx+1 S D)$ : Moderately Low Security.

\section{Perceived parental security profiles and drinking behaviors}

Preliminary analyses showed that perceived parental security profiles were not contingent upon gender, $\chi^{2}(4)=9.51, p=0.05$, Cramer's $V=0.09$ or grade level, $\chi^{2}(16)=43.57, p<0.001$, Cramer's $V=0.10$. Previously, as herein, we found 'Normal' $(n=51,4.5 \%)$ and 'Alcoholiclike' $(n=6,0.53 \%)$ groups in the AAIS to have relatively few members. As previously done, three revised AAIS categories were formed [24]: (a) abstainers $=0 \quad(n=355,32 \%)$, (b) moderate drinkers $=1-41 \quad(n=569$, $50.53 \%)$, and problematic drinkers $=42-79(n=202,17.94 \%)$. Therefore, a problematic drinker was defined as anyone scoring $\geq 42$ on the AAIS. Results of a multinomial logistic regression are shown in Table 3.

In keeping with our hypotheses, it appears that adolescents with High Security profiles were the most likely to be abstainers, and adolescents with Low Security profiles were the most likely to be problematic drinkers with the other profiles falling between the two poles. When compared to adolescents with a High Security profile, Low Security adolescents were almost 8 times more likely to be a moderate drinker and 55 times more likely to be a problematic drinker than an abstainer. Youth with Moderately Low Security profiles were also far more likely to be moderate (2 times) or problematic (7 times) drinkers than abstainers when compared to High Security peers. Lower levels of risk for moderate and problematic drinking were observed among Moderately High Security and Ambivalent adolescents, though risk remained substantial when compared to High Security adolescents.

Results of Analyses of Covariance (ANCOVA) controlling for gender, grade, and school showed that AAIS alcohol behavior categories were associated with parent rules about drinking, and the association was both statistically and practically significant (Table 4). Abstainers reported the highest levels of parent rules about drinking, followed by moderate and problematic drinkers. ANCOVA results also pointed to a statistically and practically significant association between parent rules about drinking and perceived parental security profiles (Table 4). Parent rules about drinking were highest among adolescents with High Security profiles, followed in order, by adolescents with Moderately High Security, Ambivalent Security, Moderately Low Security, and Low Security profiles. 


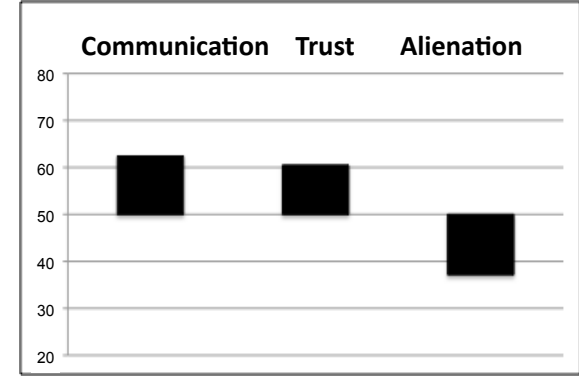

A. High Security $(n=146$ or $13 \% ; A P P=90)$

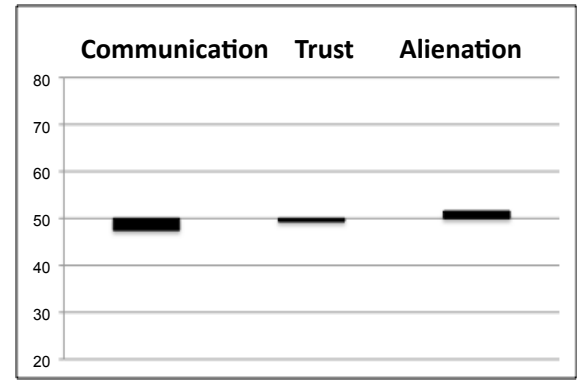

C. Ambivalent Security $(n=344$ or $31 \% ; A P P=81)$

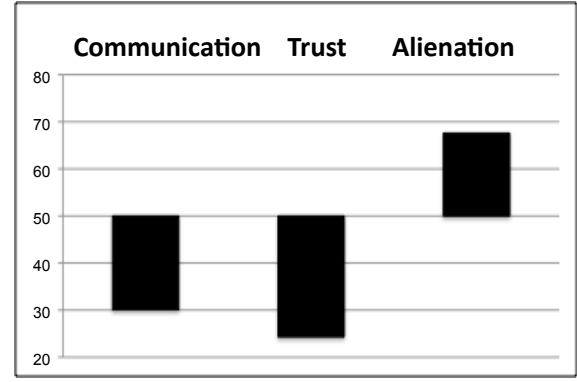

E. Low Security $(n=67$ or $6 \% ; A P P=92)$

Figure 1: Profiles are shown using $T$-scores, where 50 is the mean with a standard deviation of 10.

\section{Discussion}

The present study sought to investigate the viability of model-based clustering using IPPA-R scores, and the extent (if at all) to which clusters or profiles that would emerge would significantly and meaningfully relate to alcohol use behaviors. Five perceived parental security profiles were identified, and drinking behavior classifications were shown to be contingent upon these IPPA-R profiles. Previous research on the association between parent attachment and drinking behaviors have been mixed, with some studies showing an association [25] and some reporting little or no effect [12].

In developmental terms, van der Vorst et al. asserted that parent attachment does not affect the acquisition of drinking behaviors during adolescence, and these authors used a linear model to examine IPPA scores. By contrast, Caspers et al. [26] used a person-oriented analysis by employing the Adult Attachment Interview to identify attachment classifications (AAI; [27]), and these authors reported more illicit substance use among Insecure-Dismissing than Secure young adults. The discrepancies in findings might be explained by method. That is,

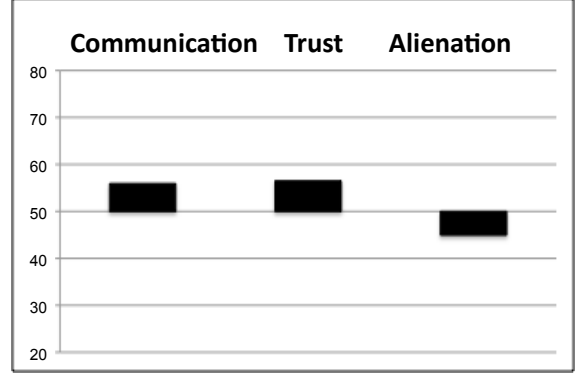

B. Moderately High Security $(n=371$ or $33 \% ; A P P=85)$

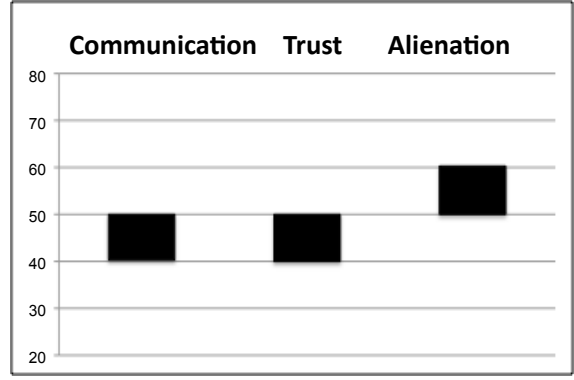

D. Moderately Low Security $(n=198$ or $18 \% ; A P P=84)$ the studies to show no effect of parent attachment on drinking have been variable-oriented (i.e., linear models). In contrast, the personoriented studies (e.g., attachment classification and IPPA-R profiles) have shown an effect, and may have therefore better accounted for the total effect of parent attachment on alcohol behaviors.

In keeping with previous research [3,13], parent rules about drinking were shown to have a negative, and substantial relationship with drinking classifications. That is, the more restrictive parents' rules about drinking were, the less likely the adolescent was to be a moderate or problematic drinker. Parent rules about drinking were also associated with perceived parental security profiles. Specifically, the more strict adolescents perceived rules about drinking, the more likely they perceived a high level of security in their relationships with parents. The implication is that parents can set limits around drinking without worrying about potential damage to their attachments with adolescents, and that more strict parental rules on drinking are protective against more problematic consumption.

Results of the present study have a few implications for 
Citation: McKay MT, Perry JL, Harvey SA, Andretta JR (2016) Alcohol Behaviors across Perceived Parental Security Profiles in Adolescents. J Child Adolesc Behav 4: 322. doi:10.4172/2375-4494.1000322

Page 5 of 7

\begin{tabular}{|c|c|c|c|c|c|c|c|c|c|}
\hline \multirow[b]{2}{*}{$\begin{array}{l}\text { Demographics/ } \\
\text { Profiles }\end{array}$} & \multicolumn{3}{|c|}{$\begin{array}{c}\text { Reference category is abstainers Moderate } \\
\text { drinkers }\end{array}$} & \multicolumn{3}{|c|}{ Problematic drinkers } & \multicolumn{3}{|c|}{$\begin{array}{c}\text { Reference category is moderate Problematic } \\
\text { drinkers }\end{array}$} \\
\hline & B (SE B) & $\operatorname{RRR}(95 \% \mathrm{Cl})$ & p-value & B (SE B) & RRR (95\% Cl) & p-value & B (SE B) & $\operatorname{RRR}(95 \% \mathrm{Cl})$ & p-value \\
\hline \multicolumn{10}{|l|}{ Gender } \\
\hline Female & -- & -- & -- & -- & -- & -- & -- & -- & -- \\
\hline \multirow[t]{2}{*}{ Male } & -0.42 & 0.66 & 0.06 & -0.48 & 0.61 & 0.22 & -0.06 & 0.93 & 0.81 \\
\hline & -0.22 & $(.43,1.02)$ & & -0.32 & $(.32,1.16)$ & & -0.27 & $(.55,1.58)$ & \\
\hline \multicolumn{10}{|l|}{ School Grade } \\
\hline Grade 8 & -- & -- & -- & -- & -- & -- & -- & -- & -- \\
\hline \multirow{2}{*}{ Grade 9} & 0.62 & 1.86 & 0.004 & 1.08 & 2.96 & 0.02 & 0.46 & 1.59 & 0.3 \\
\hline & -0.21 & $(1.22,2.82)$ & & -0.46 & $(1.19,7.34)$ & & -0.45 & $(.66,3.82)$ & \\
\hline \multirow[t]{2}{*}{ Grade 10} & 0.66 & 1.93 & 0.003 & 1 & 2.73 & 0.03 & 0.35 & 1.42 & 0.43 \\
\hline & -0.22 & $(1.25,2.98)$ & & -0.46 & $(1.11,6.75)$ & & -0.44 & $(.60,3.34)$ & \\
\hline \multirow[t]{2}{*}{ Grade 11} & 0.77 & 2.16 & 0.001 & 2.44 & 11.57 & $<0.001$ & 1.68 & 5.37 & $<0.001$ \\
\hline & -0.23 & $(1.36,3.41)$ & & -0.44 & $(4.92,27.17)$ & & -0.41 & $(2.40,11.97)$ & \\
\hline \multirow[t]{2}{*}{ Grade 12} & 1.44 & 4.22 & $<.001$ & 2.98 & 19.75 & $<0.001$ & 1.54 & 4.68 & $<0.001$ \\
\hline & -0.3 & $(2.34,7.63)$ & & -0.48 & $(7.76,50.27)$ & & -0.42 & $(2.07,10.55)$ & \\
\hline \multicolumn{10}{|c|}{ Perceived Parental Security Profiles } \\
\hline Secure & -- & -- & -- & -- & -- & -- & -- & -- & -- \\
\hline \multirow[t]{2}{*}{$\begin{array}{l}\text { Moderately High } \\
\text { Security }\end{array}$} & 0.47 & 1.59 & 0.04 & 0.54 & 1.71 & 0.2 & 0.07 & 1.08 & 0.85 \\
\hline & -0.23 & $(1.01,2.51)$ & & -0.42 & $(.75,3.93)$ & & -0.4 & $(.49,2.33)$ & \\
\hline \multirow[t]{2}{*}{ Ambivalent Security } & 0.81 & 2.25 & 0.001 & 1.14 & 3.13 & 0.007 & 0.32 & 1.39 & 0.4 \\
\hline & -0.24 & $(1.40,3.62)$ & & -0.42 & $(1.37,7.16)$ & & -0.39 & $(.65,2.98)$ & \\
\hline \multirow[t]{2}{*}{$\begin{array}{l}\text { Moderately Low } \\
\text { Security }\end{array}$} & 1 & 2.72 & $<.001$ & 1.69 & 5.42 & $<0.001$ & 0.69 & 1.99 & 0.09 \\
\hline & -0.28 & $(1.56,4.75)$ & & -0.45 & $(2.24,13.14)$ & & -0.4 & $(.91,4.37)$ & \\
\hline \multirow[t]{2}{*}{ Low Security } & 2.07 & 7.91 & 0.002 & 4.01 & 55.31 & $<0.001$ & 1.94 & 7 & $<.001$ \\
\hline & -0.65 & $(2.19,28.44)$ & & -0.73 & $(13.09,233.75)$ & & -0.45 & $(2.87,17.03)$ & \\
\hline
\end{tabular}

Note: B: Beta; SE: Standard Error of Beta; RRR: Relative Risk Ratio; Cl: Confidence Interval. Clustering at school level controlled for using dummy variables. Analyses included Parent Alcohol Rules as a control variable. Model Fit $\chi^{2}(40), p<0.001$, Pseudo $R^{2}=0.16$.

Table 3: Perceived Parental Security Profiles and Predictors Associated with revised AAIS Group Membership: MLR (shown are RRR +95\%; CI, N=1,126).

\begin{tabular}{|l|c|c|}
\hline & Mean & Standard Deviation \\
\hline Alcohol Behaviors & & \\
\hline Abstainers & 46.23 & 5.94 \\
\hline Moderate Drinkers & 41.07 & 7.49 \\
\hline Problematic Drinkers & 35.66 & 9.62 \\
\hline F $(2,1105), p<.001$ & 71.74 & \\
\hline partial $\eta^{2}$ & 0.11 & \\
\hline PPS Profiles & & \\
\hline High Security & 44.48 & 7.65 \\
\hline Moderately High Security & 42.66 & 7.86 \\
\hline Ambivalent Security & 41.21 & 8.36 \\
\hline
\end{tabular}

Note: ANCOVAs were developed controlling for grade, gender, and school. Power analysis was developed using the pwr [42] package in R-statistics [20]. Statistica significance was set to 0.01 , and power was set to 0.80 [41]. Results indicated that 0.003 and 0.004 were the cutoffs for minimally interpretable eta-squared coefficients for alcohol behaviors and PPS profiles, respectively.

Table 4: Analyses of covariance for the effect of parent rules on perceived parental security profiles and alcohol behaviors.

interventions focused on alcohol behaviors in adolescents. First, efforts might benefit from utilizing characteristics of parent attachment where relationships are strong. Specifically, communication with, and trust of parents could be used to employ parental rules on drinking, especially given that parent rules have been shown to be effective in reducing

such behavior [3]. Longitudinal studies have shown that problematic behaviors degrade relationships with parents' overtime, so this strategy might be more effective earlier rather than later in the development of drinking behaviors. For example, van der Vorst et al. [12] showed that engagement in drinking behaviors caused perceived attachment with parents to decrease during adolescence.

These data also suggest that family therapy focused on aspects of parent attachment might be beneficial in alcohol related interventions. Diamond and Siqueland [28] introduced Attachment-Based Family Therapy (ABFT), and results of studies on ABFT in adolescents were promising. The focus of ABFT is on expanding lines of communication and feelings of trust between adolescents and their parents, thereby diminishing feelings of alienation. Studies to include ABFT in adolescents have shown reductions in anxiety, depression, family conflict, and suicidal ideation $[29,30]$. It would be important to know if ABFT was also an effective intervention for problematic drinkers, and, or, an effective preventative effort among abstainers and moderate drinkers. For one, ABFT might prove a useful method for establishing parent rules about drinking.

It is also possible that bolstering perceived parental security in therapeutic settings might deflect peer pressure susceptibility through self-efficacy. Parental attachment has been shown to be indicative of selfefficacy [31], and self-efficacy has been shown to be protective against 
peer pressure susceptibility [32]. In fact, psychosocial maturation is one reason why adolescents appear better able to resist peer pressure late in adolescence [33]. Future inquiry should include a longitudinal study on the pathway between IPPA-R profiles and peer pressure susceptibly through self-efficacy.

The results of the present study in respect of the relationship between alcohol use behaviors and perceived parental security profiles are strengthened by some additional findings which are fully consistent with an emerging literature. Firstly, the results of the regression models displayed in Table 3 suggest that girls are as likely to drink problematically as boys. Historically this was not the case in $\mathrm{NI}$, where boys appeared more at risk of problematic drinking than girls [34]. However, a growing body of research has begun to suggest that a convergence has taken place so that girls are as likely as boys to drink problematically $[35,36]$. The results of the present study support this suggested convergence. Secondly, the results for school grade (a proxy measure of age) are in line with much other literature [35-37], which has suggested that between ages 10 and 18, the prevalence of alcohol consumption increases with each increasing year band, so that while adolescent consumption may begin in early adolescence it works towards a peak in later adolescence.

\section{Limitations}

The present study included survey research on parent attachment patterns, and researchers have shown that structured interviews are a strong alternative [38]. Observations of adolescent attachment behavior might also be possible, though this method has not been advised in adolescence [39]. Further, data in the present study were cross-sectional. It would be important to know the stability, and effect of perceived parental security profiles on alcohol involvement over time. Replications in diverse populations are needed to determine the generalizability of IPPA-R profiles. Perhaps the influence of perceived parental profiles on drinking behaviors will be found to differ across cultures. It was noted that four of the five identified in the present study were also shown in African Americans with juvenile court contact in the United States. Another limitation was that data were solely self-reports provided by adolescents. This method of data collection has been criticized by some for yielding results that are shaped by mono-informant bias, and not the intended constructs [40-44]. Finally, no data were available for socioeconomic status, and future studies might include such data as it is possible that socioeconomic status is meaningfully related to both parental security and alcohol use behaviors.

\section{References}

1. Armsden G, Greenberg M (1987) The inventory of parent and peer attachment: Individual differences and their relationship to psychological well-being in adolescence. J Youth Adolescence 16: 427-454.

2. Gullone E, Robinson K (2005) The Inventory of Parent and Peer AttachmentRevised (IPPA-R) for children: A psychometric investigation. Clin Psychol Psychother 12: 67-79.

3. McKay MT (2015) Parental rules, parent and peer attachment, and adolescent drinking behaviors. Subst Use Misuse 50: 184-188.

4. Bergman LR, Magnusson D, El-Khouri BM (2003) Studying individual development in an interindividual context: A person-oriented approach. Lawrence Erlbaum Associates, Inc. Mahwah, NJ.

5. Andretta JR, Worrell FC, Mello ZR, Dixson DD, Baik SH (2013) Demographic group differences in adolescents' time attitudes. J Adolescence 36: 289-301.

6. Worrell FC, Andretta JR, Woodland MH (2014) Cross Racial Identity Scale (CRIS) scores and profiles in African American adolescents involved in the juvenile justice system. J Couns Psychol 61: 570-580.

7. Andretta JR, Ramirez AM, Barnes ME, Odom T, Robertson-Adams S, et al.
(2015) Perceived parental security profiles in African American adolescents involved in the juvenile justice system. J Fam Psychol 29: 884-894.

8. Fraley C, Raftery AE (2002) Model-Based clustering, discriminant analysis, and density estimation. J Am Stat Assoc 97: 611-631.

9. Anderson AR, Henry CS (1994) Family system characteristics and parental behaviors as predictors of adolescent substance abuse. Adolescence 29: 405420 .

10. Cooper ML, Shaver PR, Collins NL (1998) Attachment styles, emotion regulation, and adjustment in adolescence. J Pers Social Psychol 74: 13801397.

11. Kwakman AM, Zuiker FAJM, Schippers GM, de Wuffel FJ (1988) Drinking behavior, drinking attitudes, and attachment relationship of adolescents. J Youth Adolescence 17: 247-253.

12. Van der Vorst H, Engels RCME, Meeus W, Dekovic M (2006) Parenta attachment, parental control, and early development of alcohol use: A longitudinal study. Psychol Addict Behav 20: 107-116.

13. Nash SG, McQueen A, Bray JH (2005) Pathways to adolescent alcohol use: family environment, peer influence, and parental expectations. J Adolescent Health : Official Publication of the Society for Adolescent Medicine 37: 19-28.

14. Henry KL, Oetting ER, Slater MD (2009) The role of attachment to family, school, and peers in adolescents' use of alcohol: A longitudinal study of withinperson and between-persons effects. J Couns Psychol 56: 564-572.

15. Maas C, Hox J (2005) Sufficient sample sizes for multilevel modeling Methodology: Eur J Res Meth Behav Social Sci 1: 86-92.

16. Mayer J, Filstead WJ (1979) The Adolescent Alcohol Involvement Scale. An instrument for measuring adolescents' use and misuse of alcohol. J Stud Alcohol 40: 291-300.

17. Shields A, Campfield D, Miller C, Howell R, Wallace K, et al. (2008) Score reliability of adolescent alcohol screening measures: A meta-analytic inquiry. $J$ Child Adolescent Subst Abuse 17: 75-97.

18. Van der Vorst $\mathrm{H}$, Engels RCME, Meeus W, Deković M, Van Leeuwe J (2005) The role of alcohol-specific socialization in adolescents' drinking behavior. Addict 100: 1464-1476

19. Fraley AC, Raftery A, Scrucca L (2014) Package "mclust".

20. Team RC (2014) R: A language and environment for statistical computing. Vienna, Austria.

21. Oh MS, Raftery AE (2007) Model-based clustering with dissimilarities: A Bayesian approach. J Comput Graph Stat 16: 559-585.

22. Mun EY, von Eye A, Bates ME, Vaschillo EG (2008) Finding groups using model-based cluster analysis: Heterogeneous emotional self-regulatory processes and heavy alcohol use risk. Dev Psychol 44: 481-495.

23. Fritsch A (2012) mcclust: Process on MCMC sample of clustering R package version 1.0 .

24. McKay MT, Andretta JR, Magee J, Worrell FC (2014) What do temporal profiles tell us about adolescent alcohol use ? Results from a large sample in the United Kingdom. J Adolescence 37: 1319-1328.

25. Andres F, Castanier C, Le Scanff C (2014) Attachment and alcohol use amongst athletes: The mediating role of conscientiousness and alexithymia Addict Behav 39: 487-90.

26. Caspers K, Cadoret R, Langbehn D (2005) Contributions of attachment style and perceived social support to lifetime use of illicit substances. Addict Behav 30: 1007-1011.

27. Main M, Goldwyn R (1985) Adult attachment classification system.

28. Diamond G, Siqueland L (1995) Family therapy for the treatment of depressed adolescents. Psychother 32: 77-90.

29. Diamond GS, Wintersteen MB, Brown GK, Diamond GM, Gallop R, et al. (2010) Attachment-based family therapy for adolescents with suicidal ideation: A randomized controlled trial. J Am Acad Child Adolescent Psychiat 49: 122-131.

30. Diamond GS, Reis BF, Diamond GM, Siqueland L, Isaacs L (2002) Attachmentbased family therapy for depressed adolescents: A treatment development study. J Am Acad Child Adolescent Psychiat 41: 1190-1196.

31. Wei M, Russell DW, Zakalik Ra (2005) Adult attachment, social self-efficacy, 
Citation: McKay MT, Perry JL, Harvey SA, Andretta JR (2016) Alcohol Behaviors across Perceived Parental Security Profiles in Adolescents. J Child Adolesc Behav 4: 322. doi:10.4172/2375-4494.1000322

self-disclosure, loneliness, and subsequent depression for freshman college etudents: A longitudinal study. J Couns Psychol 52: 602-614.

32. Caprara GV, Barbaranelli C, Pastorelli C, Cervone D (2004) The contribution of self-efficacy beliefs to psychosocial outcomes in adolescence: Predicting beyond global dispositional tendencies. Pers Indiv Diff 37: 751-763.

33. Sumter SR, Bokhorst CL, Steinberg L, Westenberg PM (2009) The developmental pattern of resistance to peer influence in adolescence: Will the teenager ever be able to resist? J Adolescence 32: 1009-1021.

34. Loretto WA (1994) Youthful drinking in Northern Ireland and Scotland: Preliminary results from a compartive study. Drugs: Educ, Prev, Policy 1: 143152.

35. McKay MT, Percy A, Cole JC (2013) Present orientation, future orientation and alcohol use in Northern Irish adolescents. Addict Res Theory 21: 43-51.

36. Northern Ireland Statistics and Research Agency (2008) Young Person's Behavior and Attitude Survey NISRA, Belfast 127-143.

37. Percy A, Iwaniec D (2010) Teenage drinking: Causes and consequences. Lambert Academic, Saarbruken.

38. Allen JP, Porter M, McFarland C, McElhaney KB, Marsh P (2007) The relation of attachment security to adolescents' paternal and peer relationships, depression, and externalizing behavior. Child Develop 78: 1222-1239.

39. Solomon J, George C (2008) The measurement of attachment security and related constructs in infancy and early childhood. In: Cassidy J, Shaver PR (Edn.), Handbook of attachment: Theory, research, and clinical applications (2ndedn) Guildford Press, New York, pp. 383-416.

40. Podsakoff PM, MacKenzie SB, Lee JY, Podsakoff NP (2003) Common method biases in behavioral research: A critical review of the literature and recommended remedies. J Appl Psychol 88: 879-903.

41. Ellis PD (2010) The essential guide to effect sizes: Statistical power, metaanalysis, and the interpretation of research results. Cambridge University Press, Cambridge, United Kingdom.

42. Champely S (2012) pwr: Basic functions for power analysis. Retrieved December 02, 2014

43. McKay MT, Dempster M (2016) The reliability and factorial validity of the Adolescent Alcohol Involvement Scale in a large sample in the United Kingdom. J Subst Use 21: 177-178.

44. Moineddin R, Matheson FI, Glazier RH (2007) A simulation study of sample size for multilevel logistic regression models. BMC Med Res Methodol 7: 34 